Article

\title{
Sustainable Portfolio Optimization with Higher-Order Moments of Risk
}

\author{
Kanwal Iqbal Khan ${ }^{1, *}$, Syed M. Waqar Azeem Naqvi ${ }^{2}$, Muhammad Mudassar Ghafoor ${ }^{3}$ and \\ Rana Shahid Imdad Akash 4 \\ 1 Institute of Business \& Management, University of Engineering and Technology, Lahore 54000, Pakistan \\ 2 School of Continuing Studies, McGill University, Montreal, QC H3A3R1, Canada; swazeem786@gmail.com \\ 3 Director, University of the Punjab, Jhelum 49600, Pakistan; administrator@pujc.edu.pk \\ 4 School of Business Management, NFC-IEFR, Faisalabad 38000, Pakistan; shahid.imdad@yahoo.com \\ * Correspondence: kanwal.khan@uet.edu.pk
}

Received: 17 February 2020; Accepted: 2 March 2020; Published: 5 March 2020

check for updates

\begin{abstract}
Sustainable economic growth and development of stock market plays an important role in diversifying the investment opportunities that can be assessed accordingly. However, a true diversification in portfolio is impossible without inclusion of higher-order moments, skewness and kurtosis. However, the risk-taking behavior of investors is modelled with the help of higher-order moments of risk. Therefore, this study is intended to construct optimal portfolios and efficient frontiers with the inclusion of higher-order moments of risk. The findings show that optimized portfolios with inclusion of skewness and kurtosis are sustainable and significantly different than those from mean-variance optimized portfolios which show asymmetric and fat-tail risk. Results further confirm its significance in balancing the additional risk dimensions and returns in Asian emerging stock markets for sustainable returns. The results also endorse that induction of skewness and kurtosis affects portfolio allocation weights and expected returns. Therefore, this study strongly recommends the inclusion of higher moments of risk for optimization to curtail their effect and sub-optimal decisions.
\end{abstract}

Keywords: sustainable returns; higher moments; portfolio optimization; skewness; kurtosis; efficient frontiers

\section{Introduction}

In today's world the stock market is considered a gauge for economic development and growth of a country that makes the stock market a vital organ to look at an economy [1,2]. The stock market helps investors to predict the outcome of an economy, and whether it is sustainable or not [3,4], since the stock market is considered a barometer of economic growth, activities, and other economic functions [5]. These functions include security trading for businesses to raise necessary capital and for investors to accumulate wealth on their invested money as well as liquidate their positions as they need funds. Stock markets not only provide investors ways to invest efficiently and effectively but also ways of diversification in various asset classes and indices [2,6]. By diversifying the asset allocation decisions, the long-term economic growth can be sustained which is beneficial for investors as well as for the country. Assets allocations that are not well diversified lead to uncertainty about future outcomes and sustainable economic growth increase risk.

The important benefit of diversification is that it creates a balance between return and risk and this diversification idea is introduced by Markowitz (1952) through his modern portfolio theory $[7,8]$. The idea of modern portfolio theory mean-variance method was to maximize expected returns at given level of risk or to reduce risk at a given level of expected return. Since its introduction, it has gained 
recognition for optimization of portfolio in finance practitioners. However, there is major ambiguity in mean-variance framework that returns' distribution is normal $[9,10]$. This normality assumption states that variance and expected returns truly represent the return distribution. Because of this assumption the optimization process understates the true investment associated risk, as this assumes that variance is an efficient proxy of risk [11]. Many finance studies confirm that return's distribution of an asset is non-normal and can be skewed either positive or negative with excess kurtosis [12,13].

The objective of this study is to calculate the sustainable proportionated optimized portfolios for various investors with different risk preferences and asset pricing. The efficient frontiers construction is another objective of this study by including the higher-order moments of risk to attain sustainable risk adjusted portfolios. In the presence of negative skewness in asset returns the probability of negative returns are high as compare to positive returns and if there is positive skewness in asset returns, the probability of getting positive returns are higher than negative $[6,14]$. However, excess kurtosis indicates the high probability of extreme events either positive or negative called fat-tail risk or leptokurtic risk. The presence of skewness and kurtosis in financial returns indicate the necessary inclusion of these moments of risk to optimize the portfolio and its behavioral description $[15,16]$. Optimization based on mean-variance can lead to understated risk, which could result in an inefficient portfolio. The presence of kurtosis and skewness and their inclusion in mean-variance framework create a hurdle to finding a balance among these objectives. Inclusion of third and fourth moment of risk make this multi-objective problem non-smooth and non-convex [17]. Due to non-convexity many studies neglected the kurtosis as well as investor risk preferences and trading strategies and focus on three moments for optimization of portfolios.

To deal with this issue, this study uses a multi-objective Polynomial Goal Programming (PGP) approach $[5,18]$. This method can find optimal portfolio based on various criteria as well as including investors' preferences [5]. In this study, we include skewness and kurtosis by keeping investors preferences in line beside conventional mean-variance criteria in eight Asian emerging economies. We came up with idea that third and fourth moments of risk play a vital role in formulating optimized portfolios. Our results suggest that investors who want to minimize risk in all four dimensions need to expect lower return. The article is ordered as follows: Section 2 is review of literature, Section 3 is data and methodology, and Sections 4 and 5 contain our results and conclusion, respectively.

\section{Literature Review}

A mixture of collected stocks is called a portfolio. The problem with optimization of portfolio is one of the common problems in the world of finance, and asset diversification could be the possible solution to counter this [3]. Investors always look for a portfolio which provides maximum return at minimum risk [7]. Previous studies presented the notion of diversification that by dividing available capital into smaller parts and investing those small portions of the capital into various small investments can spread the risk against a single large risk in case of a single investment [15]. However, a rational for portfolio diversification is missing because they are unable to diversify the non-systematic risk (diversifiable risk) [19]. Portfolio variance of bonds is used to measure risk and argues that risk can be minimized if the bonds in the portfolio are either not correlated or have very low level of correlation among selected securities and number of bonds are increased in the portfolio [20]. This was later extended through modern portfolio theory that explain investor decisions are based on the expected return at a given level of risk [8,21]. A framework called mean-variance was developed to optimize the portfolios based on these two moments of risk. The main assumption of this framework is that the returns' distribution is normal or a quadratic utility function which depends on mean and variance.

The different securities combined in a portfolio using mean-variance is an efficient frontier which can be plotted using covariance between securities is called minimum risk portfolio. Tobin's separation theorem explained an efficient frontier is developed by minimizing portfolio risk [22]. Modern portfolio theory has played a vital role in capital asset pricing [23-25]. If investors have a risky asset portfolio regardless of their risk preferences the held portfolio is a market portfolio. A portfolio can be analyzed 
in two parts. Firstly, analysis of individual securities and the other one is portfolio analysis [26]. The analysis of portfolio part is related to modern portfolio theory which helps in identification and development of efficient frontier of various portfolio sets with high expected return but at the same level of risk or at minimum risk at a given expected return [27]. Selection of a portfolio from a given optimized set of portfolio depends on investor risk preference (liking to take risk) because efficient frontier is the same for all investors. However, modern portfolio theory runs on various assumptions. First, investors are always hesitant in taking risks. Second, investors' decisions are highly dependent on what they get back in the form of return against the risk they bear. Third, a vital assumption is whether, at disposal of portfolio, an investor created wealth by maximizing returns. Fourth, investors go after a one-time investment horizon and lastly, taxes and cost of transaction is absent [28].

Modern portfolio theory assumptions state that financial returns are normally distributed. However, several researches on various market unveil that financial returns are not distributed normally, which contradicts these assumptions. Even in the Australian market investors observed that the returns are uneven and positively skewed [29] and in the Japanese market the presence of kurtosis and skewness in returns was observed $[2,30]$. Previous studies found the positive relationship between kurtosis and volatility clustering and presence of leptokurtosis in financial returns [9]. They also confirmed that kurtosis and skewness (asymmetry) increase due to high volatility clustering in financial time series [31,32]. These studies further confirmed that financial returns are non-normal and have skewness and kurtosis. Therefore, it is essential to include these risk moments while constructing an optimized portfolio [33]. Previously, scholars stress on the inclusion of skewness and argue that incorporation of skewness not only improves the efficiency of mean-variance portfolio but also effect on optimization of portfolio and its selection [1,4,12].

In recent couple of decades, kurtosis has become a vital part when selecting a portfolio [12] and the inclusion of kurtosis is stressed while selecting and optimizing a portfolio. Inclusion of kurtosis and skewness in a portfolio selection makes it non-convex [2,34,35]. Due to non-convex characteristic after inclusion of higher-order moments, various objectives can be obtained, e.g., maximizing returns and positive skewness while at the same time minimizing variance and skewness. In order to simplify the quadratic function, studies in the past have used mean-variance model. To solve complex problems, finance literature has developed various methods over the years [36]. Such methods include non-parametric efficiency measurements or evolutionary experimental setting algorithm approach [17]. Keeping in view the previous literature, we employed the Polynomial Goal Programming (PGP) multi-objected method to incorporate third and fourth moment of risk for optimal portfolio selection.

The existing finance literature also confirms efficiency and effectiveness of PGP in solving similar problems with various contradictory risk preferences by including asymmetry (third moment of risk) according to investors' preferences to select portfolios [1]. Being a flexible method of including higher moments of risk (variance, skewness and kurtosis), PGP is helpful for optimization of portfolio as per risk preferences of investors without explicit specific utility function though inclusion of higher moments should be defined explicitly. The practical efficiency and effectiveness of PGP, as well as its preeminence over various other methods, is also validated by various researchers [37]. Used multi-objective method for optimal portfolio construction with improvements is also recommended for modern portfolio construction [38]. Furthermore, the addition of the fourth moments of risk in PGP has taken it from three dimensions to four [5]. To construct optimal portfolios of hedge funds multi-dimensional PGP is used [11,12].

\section{Methodology}

\subsection{Data}

Based on Morgan Stanley Capital International (MSCI) emerging and developed market categorization, six Asian emerging markets and two developed pacific stock markets were chosen for this study. The indices of emerging markets are SSE composite index China, CNX 500 index India, 
FTSE Burse index Malaysia, KSE 100 index Pakistan, KOPSI 200 South Korea, and TAIEX index Taiwan. While pacific developed markets indices include Hang Seng index Hong Kong and STI index Singapore. The selection of markets is based on MSCI capital inflow compared to other developed markets in percentage terms. According to MSCI about 60 percent of the world's financial capital movement has been associated to these markets in the last ten years. SSE composite, CNX500, FTSE Burse, KSE 100, KOPSI 200, TAIEX, Hang Seng, and STI capitalizations are CN 32.70 trillion, USD 2.27 trillion, RM509 trillion, USD 85 billion, KRW 1475 trillion, NT\$36,413 trillion, USD 4.4 trillion, and USD 773 billion respectively. The emerging markets and pacific developed markets mix create an enormous demand and investors with different risk preferences looking for sustainable returns. To analyzing an optimized portfolio with sustainable growth and return it is vital to include higher moments of risk which can help avoiding sub-optimal decisions by investors. MSCI capital flow criteria has been used while selecting these markets. The higher return expectation is one of the factors of this inflow. Ten-year monthly closing index is selected from 2009 to 2019 and returns are calculated by using natural log ratio. The indices data has been retrieved from Yahoo finance and reason of using monthly indices returns are that these are less noisy and sustainable. The monthly returns keep investing perspective rather daily trading perspective which contains more volatility and distort real outcome. The other reason for using monthly returns is that a comparison can be drawn with other similar investing opportunities like mutual fund, hedge funds and segregated fund in these markets which publish their performance on a monthly basis as well. The log returns are used to calculate optimized portfolios and optimization in drawing efficient frontiers

$$
R_{t}=\log \left(P_{t} / P_{t-1}\right)
$$

To calculate asset $i$ return and variance:

$$
\begin{gathered}
\bar{R}_{t}=\frac{\sum_{j=1}^{n} R_{i j}}{n}, \sigma_{t}^{2}=\frac{\sum_{j=1}^{n}\left(R_{i j}-\bar{R}_{t}\right)^{2}}{n} \\
\bar{R}_{t}=\text { Asset } i \text { expected returns, } \\
R_{i j}=\text { Asset } i \text { actual returns at time } j, \\
\sigma_{t}^{2}=\text { Asset } i \text { variance } \\
n=\text { Number of observations }
\end{gathered}
$$

\subsection{Skewness and Kurtosis Inclusion for Sustainable Optimization}

Various researches agree on the non-normality of returns $[13,29,30]$. Based on this argument the inclusion of higher moments is vital for a sustainable optimized portfolio and efficient frontier. Many studies emphasize on the inclusion of skewness because the third moment of risk's inclusion enhances the efficiency in optimization as compared to traditional mean-variance optimization $[1,10,11]$. Over the last few decades the fourth moment of risk has gained the attention of finance academicians, professional and investors [39]. Many studies have been conducted concerning the importance of inclusion of kurtosis for sustainable optimization of portfolios. In recent years, kurtosis has become very important and received much attention [27,34,35].

Equation (2) represents the expected return of a portfolio. Equation (3) represents portfolio variance. The mean-variance equations represent return distribution's first two components which are essential for optimization. Portfolio optimization describes a best possible combination of securities.

$$
\text { Mean }=R(x)=X^{T} \bar{R}=\sum_{i=1}^{n} W_{i} R_{i} .
$$




$$
\text { Mean }=R(x)=X^{T} \bar{R}=\sum_{i=1}^{n} W_{i} R_{i}
$$

Portfolio skewness Equation (4) shows returns' skewness and co-skewness which is individual coefficient's weighted sum. Portfolio kurtosis Equation (5) shows indices returns' kurtosis and co-kurtosis which is coefficient's weighted sum.

$$
\begin{gathered}
\text { Skewness }=S(x)=E[R-\bar{R}]^{3}=\sum_{i=1}^{n} \sum_{j=1}^{n} \sum_{k=1}^{n} w_{i} w_{j} w_{k} s_{i j k}(i \neq j) \\
\text { Kurtosis }=K(x)=E[R-\bar{R}]^{4}=\sum_{i=1}^{n} \sum_{j=1}^{n} \sum_{k=1}^{n} \sum_{l=1}^{n} w_{i} w_{j} w_{k} w_{l} k_{i j k l}(i \neq j) .
\end{gathered}
$$

To standardize the portfolio skewness and kurtosis, divide portfolio skewness and kurtosis with portfolio variance, then a new equation is.

The variance-covariance matrix equation is as under (See Appendix A Table A1):

$$
\sigma_{i j}=E\left[\left(R_{i}-\bar{R}_{i}\right)\left(R_{j}-\bar{R}_{j}\right)\right]
$$

To calculate individual, two, and three stock coefficient of skewness, co-skewness is $S_{i i i}, S_{i i j}$, and $S_{i j k}$ respectively, we use notations from Equations (7)-(10). The expression of portfolio skewness and co-skewness is as follows (See Appendix A Table A2):

$$
\begin{gathered}
S_{p}=\frac{\sum_{i=1}^{n} \sum_{j=1}^{n} \sum_{k=1}^{n} w_{i} w_{j} w_{k} s_{i j k}}{\sum_{i=1}^{n} \sum_{j=1}^{n} w_{i} w_{j} \sigma_{i j}} \\
S_{i i i}=E\left[\left(R_{i}-\bar{R}_{i}\right)^{3}\right], \\
S_{i i j}=E\left[\left(R_{i}-\bar{R}_{i}\right)^{2}\left(R_{j}-\bar{R}_{j}\right)\right], \\
S_{i j k}=E\left[\left(R_{i}-\bar{R}_{i}\right)\left(R_{j}-\bar{R}_{j}\right)\left(R_{k}-\bar{R}_{k}\right)\right]
\end{gathered}
$$

$k_{i i i i}, k_{i i j j}, k_{i j j j}$ and $k_{i j k l}$ are coefficients of kurtosis-co-kurtosis. The notations of portfolio kurtosis and co-kurtosis used for calculation are as follows:

$$
\begin{gathered}
K_{p}=\frac{\sum_{i=1}^{n} \sum_{j=1}^{n} \sum_{k=1}^{n} \sum_{l=1}^{n} w_{i} w_{j} w_{k} w_{l} k_{i j k l}}{\sum_{i=1}^{n} \sum_{j=1}^{n} w_{i} w_{j} \sigma_{i j}} \\
k_{i i i i}=E\left[\left(R_{i}-\bar{R}_{i}\right)^{4}\right], \\
k_{i i j j}=E\left[\left(R_{i}-\bar{R}_{i}\right)^{2}\left(R_{j}-\bar{R}_{j}\right)^{2}\right], \\
k_{i j j j}=E\left[\left(R_{i}-\bar{R}_{i}\right)\left(R_{j}-\bar{R}_{j}\right)^{3}\right], \\
k_{i j k l}=E\left[\left(R_{i}-\bar{R}_{i}\right)\left(R_{j}-\bar{R}_{j}\right)\left(R_{k}-\bar{R}_{k}\right)\left(R_{l}-\bar{R}_{l}\right)\right]
\end{gathered}
$$

After comparing Equations (7)-(15), we may see how difficult is to incorporate third and fourth moment against mean-variance. We use PGP approach to consolidate our objectives of higher-order moments inclusion and maximize portfolio return, minimize variance, maximize skewness, and minimize kurtosis. By achieving our objective, we can get a sustainable and reliable portfolio [5,7].

$$
\text { Mean }=R(x)=X^{T} \bar{R}(\text { Maximize })
$$




$$
\begin{gathered}
\text { Variance }=V(x)=X^{T} V X(\text { Minimize }) \\
\text { Skewness }=S(x)=E\left(X^{T}(R-\bar{R})\right)^{3} \text { (Maximize) } \\
\text { Kurtosis }=K(x)=E\left(X^{T}(R-\bar{R})\right)^{4} \text { (Minimize) }
\end{gathered}
$$

We conditioned our solution as $W=1, X \geq 5 \%$ and $X \leq 50 \%$

Four moment optimized portfolio parameters are $R^{*}, V^{*}, S^{*}, K^{*}$, which are also called aspired values. The expected value of return distribution is $\bar{R}$ in above equations and $X^{T}$ is weight transpose vector which represents percentage allocation of funds in a portfolio. Four parameters $\lambda_{1}, \lambda_{2}, \lambda_{3}, \lambda_{4}$ are used to include investors' preferences towards higher moments of risk. To combine multi-objectives into one objective to include higher risk preferences we use the following Equation (20). There is a two-step solution to multi-objective problems. First, investors risk preferences are independent, and solution is not dependent on risk preferences. In the second step higher moments of risk are included according to risk preferences and appropriate solution is picked as per risk preferences.

$$
\mathrm{A}=\left|\frac{d_{1}}{R^{*}}\right| \lambda_{1}+\left|\frac{d_{2}}{V^{*}}\right| \lambda_{2}+\left|\frac{d_{3}}{S^{*}}\right| \lambda_{3}+\left|\frac{d_{4}}{K^{*}}\right| \lambda_{4}
$$

$d_{1}, d_{2}, d_{3}, d_{4}$ are objective variables and estimate actual moment deviation against aspired values. For computation of variance-co-variance, skewness-co-skewness and kurtosis-co-kurtosis matrices, we have used VBA in Excel and Solver to allocate weights at optimized and sustainable level of A at various risk preferences.

\section{Empirical Analysis and Results}

A rational and inquisitive investor must be all set to see the impact of these often-overlooked risk dimensions in selected markets. Table 1 has the answer of this curiosity. Individual markets' annualized returns are quite attractive, with highest $17.04 \%$ KSE100, 15.60\% CNX500, 8.16\% FTSE, $6.36 \%$ HIS, $5.76 \%$ STI, $5.40 \%$ KOPSI, $4.68 \%$ TESEC, and lowest 3.72\% SCI. The return to risk ratio is quite high with highest annualized standard deviation 29.96\% SCI, 27.85\% CNX500, 27.61\% KSE100, $21.96 \%$ HSI, 19.75\% TESEC, 19.09\% STI, 17.18\% KOPSI, and 12.92\% FTSE. The average annualized return of these markets is $8.34 \%$ which is quite impressive but at the cost of high average $22.04 \%$ annualized volatility. The skewness and kurtosis indicate the true entrenched risk in these markets. Skewness and kurtosis range from -0.292 (lowest) to -1.192 (highest), 1.451 (platykurtic) to 10.46 (leptokurtic) respectively. The average skewness and kurtosis in these markets are -0.8166 and 4.277 , which is confirmation of higher moments of risk in these markets. These numbers show fat-tail risk, negatively skewed and leptokurtic return's distribution which indicate the probability of more negative returns and high chances of extreme losses and events.

Table 1 contains the descriptive statistics and ranking based on coefficient of variance, skewness, and kurtosis of selected markets. Based on Coefficient of Variation, the less risky market index is the FTSE, while the riskiest is the SCI index, which means high risk per percent of return. Skewness based ranking shows the STI index as highly risky, which shows high risk per percent of return, while TESEC has lowest asymmetric risk. The kurtosis ranking indicates the KSE100 index is the riskiest, with the presence of fat-tail (leptokurtic (narrow) peak), while the SCI has wider peak (platykurtic distribution). Each risk measure provides different level of risk in these markets, which indicates the need of inclusion of higher moments of risk for portfolio optimization. We solve Equations (16)-(19) to get aspired level individually. The first section of Table 2 shows weight allocated to individual index and the second section has aspired levels based on mean, variance, skewness, and kurtosis individually. 
Table 1. Descriptive Statistics Risk and Returns.

\begin{tabular}{cccccccccc}
\hline \multicolumn{1}{c}{$\begin{array}{c}\text { Assets } \\
\text { Names of } \\
\text { Markets }\end{array}$} & Average & $\begin{array}{c}\text { Standard } \\
\text { Deviation }\end{array}$ & $\begin{array}{c}\text { Sharpe } \\
\text { Ratio }\end{array}$ & Skewness & Kurtosis & $\begin{array}{c}\text { Coefficient } \\
\text { of Variation }\end{array}$ & $\begin{array}{c}\text { Ranking } \\
\mathbf{1}\end{array}$ & $\begin{array}{c}\text { Ranking } \\
\mathbf{2}\end{array}$ & $\begin{array}{c}\text { Ranking } \\
\mathbf{3}\end{array}$ \\
\hline SCI & 0.0031 & 0.0865 & 0.035 & -0.587 & 1.451 & 27.903 & 1 & 6 & 8 \\
HIS & 0.0053 & 0.0634 & 0.083 & -0.835 & 2.94 & 11.962 & 3 & 3 & 5 \\
CNX500 & 0.013 & 0.0804 & 0.161 & -0.575 & 3.74 & 6.1846 & 6 & 7 & 4 \\
FTSE & 0.0068 & 0.0373 & 0.183 & -0.754 & 4.3 & 5.4852 & 8 & 4 & 3 \\
KSE100 & 0.0142 & 0.0797 & 0.177 & -1.681 & 10.46 & 5.6126 & 7 & 2 \\
STI & 0.0048 & 0.0551 & 0.087 & -1.192 & 7.01 & 11.479 & 4 & 1 \\
KOPSI & 0.0045 & 0.0496 & 0.09 & -0.617 & 2.65 & 11.022 & 5 & 5 \\
TESEC & 0.0039 & 0.057 & 0.067 & -0.292 & 1.67 & 14.6153 & 2 & 8 \\
\hline
\end{tabular}

Ranking 1 = Coefficient of Variation CV, Ranking 2 = Skewness, Ranking 3 = Kurtosis. Source: Author's calculations.

Table 2. Aspired levels with individual moment.

\begin{tabular}{ccccc}
\hline Objectives/Markets & $\begin{array}{c}\text { Aspired Mean } \\
\text { Portfolio }\end{array}$ & $\begin{array}{c}\text { Aspired Variance } \\
\text { Portfolio }\end{array}$ & $\begin{array}{c}\text { Aspired Skewness } \\
\text { Portfolio }\end{array}$ & $\begin{array}{c}\text { Aspired Kurtosis } \\
\text { Portfolio }\end{array}$ \\
\hline SCI & 0.050 & 0.050 & 0.050 & 0.050 \\
HIS & 0.050 & 0.050 & 0.050 & 0.050 \\
CNX500 & 0.200 & 0.062 & 0.050 & 0.098 \\
FTSE & 0.050 & 0.407 & 0.050 & 0.119 \\
KSE100 & 0.500 & 0.264 & 0.217 & 0.237 \\
STI & 0.050 & 0.050 & 0.050 & 0.050 \\
KOPSI & 0.050 & 0.066 & 0.050 & 0.137 \\
TESEC & 0.050 & 0.050 & 0.483 & 0.260 \\
\hline Mean & 0.01212 & 0.00269 & -0.914 & 4.4538 \\
Variance & 0.00846 & 0.00147 & -0.597 & 3.9218 \\
Skewness & 0.00678 & 0.00188 & -0.132 & 2.1109 \\
Kurtosis & 0.00766 & 0.00171 & -0.257 & 3 \\
Desired Level & 0.01212 & 0.00147 & -0.132 & 3 \\
\hline
\end{tabular}

Source: Author's calculations.

After solving Equation (16), based on our individual aspired level calculation by investing $50 \%$ in KSE100, 20\% in CNX500 and 5\% in each of remaining markets an investor can get a maximum return of 0.01212. A minimum variance 0.00147 can be obtained after solving Equation (17). The solution of Equations (18) and (19) gives a maximum skewness of -0.132 and minimum kurtosis of 3, respectively. These optimal levels are obtained by solving each equation separately, and most investors make decisions based on various moments and risk preferences. Our results show that the inclusion of skewness and kurtosis to obtain optimal level reduces the returns and increases variance. This indicates the importance of higher moments of risk to obtain a sustainable and optimal portfolio.

We evaluated nine portfolios by incorporating various risk preferences and outcomes as stated in Table 3. $\lambda_{1}, \lambda_{2}, \lambda_{3}, \lambda_{4}$ are the investor preferences of mean, variance, skewness, and kurtosis respectively. At the time of estimation of optimal portfolios, the higher value shows higher significance to the moment. Mean-variance is the benchmark Portfolio 1 which is used for comparison with other obtained multi-objective portfolios. The preferences $(3,1,1,0),(3,1,2,1)$ and $(3,1,3,1)$ in Portfolios 2 , 5 and 7 show investor's inclination towards higher returns. The other portfolios $(1,3,1,1),(1,1,1,3)$, $(1,3,1,3),(1,1,3,0)$ and $(1,1,0,3)$ show investor's various risk preferences while optimizing a portfolio. These risk preferences include variance, skewness and kurtosis. Portfolio $5(3,1,2,1)$ is an aspiring portfolio trying to incorporate all the risk dimensions. 
Table 3. Weights and different risk preferences for sustainable portfolios.

\begin{tabular}{cccccccccc}
\hline & 1 & 3 & 1 & 1 & 3 & 1 & 3 & 1 & 1 \\
Calculated Portfolios & 1 & 1 & 3 & 1 & 1 & 3 & 1 & 1 & 1 \\
$\left(\lambda_{1}, \lambda_{2}, \lambda_{3}, \lambda_{4}\right)$ & 0 & 1 & 1 & 1 & 2 & 1 & 3 & 3 & 0 \\
& 0 & 0 & 1 & 3 & 3 & 3 & 1 & 0 & 3 \\
\hline Markets/Results & 1 & 2 & 3 & 4 & 5 & 6 & 7 & 8 & 9 \\
\hline SCI & 0.05 & 0.05 & 0.05 & 0.05 & 0.05 & 0.05 & 0.05 & 0.05 & 0.05 \\
HIS & 0.056 & 0.05 & 0.05 & 0.082 & 0.05 & 0.05 & 0.05 & 0.05 & 0.11 \\
CNX500 & 0.152 & 0.42 & 0.09 & 0.069 & 0.05 & 0.05 & 0.05 & 0.06 & 0.12 \\
FTSE & 0.064 & 0.05 & 0.06 & 0.079 & 0.05 & 0.14 & 0.05 & 0.05 \\
KSE100 & 0.491 & 0.05 & 0.22 & 0.125 & 0.25 & 0.19 & 0.22 & 0.28 & 0.06 \\
STI & 0.061 & 0.05 & 0.1 & 0.077 & 0.05 & 0.05 & 0.05 & 0.05 & 0.05 \\
KOPSI & 0.064 & 0.05 & 0.05 & 0.069 & 0.05 & 0.14 & 0.05 & 0.05 & 0.05 \\
TESEC & 0.061 & 0.27 & 0.48 & 0.45 & 0.44 & 0.33 & 0.48 & 0.41 & 0.33 \\
\hline Mean Return & 0.01065 & 0.00812 & 0.00604 & 0.00623 & 0.0072 & 0.0061 & 0.00682 & 0.0076 & 0.0077 \\
Variance & 0.0026 & 0.00241 & 0.0016 & 0.00177 & 0.00194 & 0.0016 & 0.00163 & 0.00196 & 0.00185 \\
SD & 0.051 & 0.04991 & 0.04001 & 0.04207 & 0.04408 & 0.04 & 0.043957 & 0.044307 & 0.04311 \\
Skewness & -0.8748 & -0.56606 & -0.39224 & -0.24992 & -0.1351 & -0.205 & -0.12676 & -0.1646 & -0.29558 \\
Kurtosis & 4.4983 & 4.40133 & 3.541 & 2.96 & 2.1043 & 3.27 & 2.11191 & 2.158522 & 2.901 \\
\hline
\end{tabular}

Source: Author's calculations.

We chose four portfolios, 2, 4, 8 and 9 from Table 3 to provide commentary on the argument raised and make it clearer and more visible. We changed the one preference and kept others fixed to create Sub-Portfolios 2A, 4A, 8A, and 9A from Portfolios 2, 4, 8 and 9, respectively. The eight portfolios and sub-portfolios are shown in Table 4 . We maximize skewness in $2 \mathrm{~A}$ by keeping expected return and variance constant, as in Portfolio 2. This not only helps to maximize skewness which is looked-for but also increased the kurtosis and unwanted risk. We fix the variance and kurtosis in $4 \mathrm{~A}$ and can see the increase in expected return to a desired level, but at the cost of an undesired phenomenon of skewness, which decreased. In Sub-Portfolio 8A we make skewness and variance constant and see an increase expected return at the cost of higher kurtosis. Lastly, we keep the preference of kurtosis and variance constant in Sub-Portfolio 9A. The results indicate an increase in expected return at the cost of lower skewness, which is undesirable. Our results indicate the vital importance of considering higher-order moments of risks while defining and measuring the sustainability of these optimal portfolios. Beside this, an investor must settle at lower expected returns with the inclusion of these dimensions of risk. Our results do not only challenge the mean-variance optimization which gives variance more importance with no consideration of third and fourth moment of risk. In order to make the additional risk dimension more prominent we choose an optimization based on mean-skewness and mean-kurtosis by constructing seven portfolios for each optimization. Table 5 is a base table which contains mean variance-based optimized portfolios and an efficient frontier. In Tables 6 and 7, we optimize the portfolios for skewness and kurtosis, respectively, by keeping variance fixed. The expected returns decrease notably with the inclusion of skewness and this shows the presence of risk in these market portfolios which are over asked. However, expected returns with kurtosis inclusion (Table 7) go down compared to mean-variance portfolios (Table 5) but remain higher than mean-skewness (Table 6) portfolios. This confirms the argument that to achieve sustainable expected returns, investors should go for higher moments-optimized portfolios which give a true picture of expected return. 
Table 4. Change in investor's risk preferences.

\begin{tabular}{ccccccccc}
\hline & 3 & 3 & 1 & 2 & 1 & 2 & 1 & 2 \\
Calculated Portfolios & 1 & 1 & 1 & 1 & 1 & 1 & 1 & 1 \\
$\left(\lambda_{1}, \lambda_{2}, \lambda_{3}, \lambda_{4}\right)$ & 1 & 2 & 1 & 2 & 3 & 3 & 0 & 0 \\
& 0 & 0 & 3 & 3 & 0 & 0 & 3 & 9 \\
\hline Markets/Results & 2 & $2 \mathrm{~A}$ & 4 & $4 \mathrm{~A}$ & 8 & $8 \mathrm{~A}$ & 9 & $9 \mathrm{~A}$ \\
\hline SCI & 0.05 & 0.05 & 0.05 & 0.050 & 0.05 & 0.050 & 0.05 & 0.050 \\
HIS & 0.05 & 0.05 & 0.082 & 0.050 & 0.05 & 0.050 & 0.11 & 0.050 \\
CNX500 & 0.42 & 0.37 & 0.069 & 0.070 & 0.06 & 0.050 & 0.12 & 0.123 \\
FTSE & 0.05 & 0.05 & 0.079 & 0.133 & 0.05 & 0.050 & 0.06 & 0.096 \\
KSE100 & 0.05 & 0.06 & 0.125 & 0.316 & 0.28 & 0.244 & 0.23 & 0.310 \\
STI & 0.05 & 0.05 & 0.077 & 0.050 & 0.05 & 0.050 & 0.05 & 0.050 \\
KOPSI & 0.05 & 0.05 & 0.069 & 0.126 & 0.05 & 0.182 & 0.05 & 0.123 \\
TESEC & 0.27 & 0.32 & 0.45 & 0.204 & 0.41 & 0.323 & 0.33 & 0.198 \\
\hline Mean Return & 0.00812 & 0.00801 & 0.00623 & 0.00683 & 0.0069 & 0.0071977 & 0.0077 & 0.00803 \\
Variance & 0.0024 & 0.0024 & 0.00177 & 0.00177 & 0.001756 & 0.0017561 & 0.001859 & 0.00186 \\
SD & 0.04991 & 0.04899 & 0.04207 & 0.04207 & 0.044307 & 0.044307 & 0.043118 & 0.04311 \\
Skewness & -0.56606 & -0.49258 & -0.24992 & -0.33750 & -0.1646 & -0.1646008 & -0.29558 & -0.3739 \\
Kurtosis & 4.40133 & 4.56945 & 2.96100 & 2.96017 & 2.158522 & 2.5052421 & 2.91200 & 2.9100 \\
\hline
\end{tabular}

Source: Author's calculations.

Table 5. Benchmark Mean-Variance optimized portfolios.

\begin{tabular}{cccccccc}
\hline \multirow{2}{*}{ Markets/Results } & \multicolumn{7}{c}{ Portfolios } \\
\cline { 2 - 7 } & $\mathbf{1}$ & $\mathbf{2}$ & $\mathbf{3}$ & $\mathbf{4}$ & $\mathbf{5}$ & $\mathbf{6}$ & $\mathbf{7}$ \\
\hline SCI & 0.05 & 0.05 & 0.05 & 0.05 & 0.05 & 0.05 & 0.05 \\
HIS & 0.05 & 0.05 & 0.05 & 0.05 & 0.05 & 0.05 & 0.05 \\
CNX500 & 0.062 & 0.097 & 0.132 & 0.164 & 0.195 & 0.223 & 0.248 \\
FTSE & 0.407 & 0.356 & 0.291 & 0.231 & 0.176 & 0.123 & 0.073 \\
KSE100 & 0.264 & 0.297 & 0.327 & 0.354 & 0.379 & 0.404 & 0.429 \\
STI & 0.05 & 0.05 & 0.05 & 0.05 & 0.05 & 0.05 & 0.05 \\
KOPSI & 0.066 & 0.05 & 0.05 & 0.05 & 0.05 & 0.05 & 0.05 \\
TESEC & 0.05 & 0.05 & 0.05 & 0.05 & 0.05 & 0.05 & 0.05 \\
Mean Return & 0.0085 & 0.00899 & 0.0094 & 0.0098 & 0.0102 & 0.01058 & 0.0109 \\
Variance & 0.0015 & 0.00168 & 0.00185 & 0.00201 & 0.0022 & 0.0024 & 0.0026 \\
St. Dev. & 0.0394 & 0.04141 & 0.0433 & 0.04451 & 0.0468 & 0.0487 & 0.0514 \\
Sharpe Ratio & 0.2179 & 0.21934 & 0.21926 & 0.2183 & 0.2168 & 0.2153 & 0.2134 \\
Skewness & -0.9591 & -0.98611 & -1.0081 & -1.0281 & -1.0468 & -1.065 & -1.0844 \\
Kurtosis & 5.3722 & 5.58863 & 5.76125 & 5.9205 & 6.0648 & 6.2067 & 6.3546 \\
\hline
\end{tabular}

Source: Author's calculations.

Table 6. Mean-skewness based asset allocation for optimized portfolios.

\begin{tabular}{cccccccc}
\hline Observations/Markets & \multicolumn{7}{c}{ Portfolios } \\
\cline { 2 - 7 } & $\mathbf{1}$ & $\mathbf{2}$ & $\mathbf{3}$ & $\mathbf{4}$ & $\mathbf{5}$ & $\mathbf{6}$ \\
\hline SCI & 0.050 & 0.050 & 0.050 & 0.050 & 0.050 & 0.050 \\
HIS & 0.050 & 0.050 & 0.050 & 0.050 & 0.050 & 0.050 & 0.050 \\
CNX500 & 0.050 & 0.050 & 0.058 & 0.225 & 0.311 & 0.370 & 0.050 \\
FTSE & 0.136 & 0.066 & 0.050 & 0.050 & 0.050 & 0.050 \\
KSE100 & 0.197 & 0.236 & 0.293 & 0.201 & 0.171 & 0.167 \\
STI & 0.050 & 0.050 & 0.050 & 0.050 & 0.050 & 0.050 \\
KOPSI & 0.230 & 0.215 & 0.142 & 0.050 & 0.050 & 0.050 & 0.050 \\
TESEC & 0.237 & 0.283 & 0.307 & 0.324 & 0.268 & 0.213 \\
Mean Return & 0.00661 & 0.00720 & 0.00778 & 0.0083 & 0.008697 & 0.00930 \\
Variance & 0.001516 & 0.00169 & 0.00178 & 0.00201 & 0.002211 & 0.002402 & 0.274 \\
St. Dev. & 0.03923 & 0.04061 & 0.04271 & 0.04491 & 0.046990 & 0.049041 & 0.00262 \\
Sharpe Ratio & 0.16891 & 0.17490 & 0.18011 & 0.18340 & 0.185782 & 0.188311 & 0.18950 \\
Skewness & -0.23901 & -0.18041 & -0.19530 & -0.32401 & -0.457544 & -0.55421 & -0.62521 \\
Kurtosis & 3.24180 & 2.68590 & 2.42692 & 3.03450 & 3.6218301 & 3.83841 & 3.91401 \\
\hline
\end{tabular}


Table 7. Mean-kurtosis based asset allocation for optimized portfolios.

\begin{tabular}{cccccccc}
\hline \multirow{2}{*}{ Observations/Markets } & \multicolumn{7}{c}{ Portfolios } \\
\cline { 2 - 8 } & $\mathbf{1}$ & $\mathbf{2}$ & $\mathbf{3}$ & $\mathbf{4}$ & $\mathbf{5}$ & $\mathbf{6}$ & $\mathbf{7}$ \\
\hline SCI & 0.117 & 0.050 & 0.099 & 0.090 & 0.071 & 0.050 & 0.050 \\
HSI & 0.050 & 0.050 & 0.060 & 0.067 & 0.050 & 0.050 & 0.050 \\
CNX500 & 0.050 & 0.098 & 0.156 & 0.167 & 0.230 & 0.278 & 0.337 \\
FTSE & 0.063 & 0.119 & 0.050 & 0.050 & 0.050 & 0.050 & 0.050 \\
KSE100 & 0.205 & 0.237 & 0.274 & 0.332 & 0.337 & 0.341 & 0.334 \\
STI & 0.050 & 0.050 & 0.050 & 0.050 & 0.050 & 0.050 & 0.050 \\
KOPSI & 0.415 & 0.137 & 0.191 & 0.150 & 0.104 & 0.055 & 0.050 \\
TESEC & 0.050 & 0.260 & 0.120 & 0.095 & 0.108 & 0.126 & 0.078 \\
\hline Mean Return & 0.00692 & 0.00772 & 0.00844 & 0.00913 & 0.00971 & 0.01019 & 0.01065 \\
Variance & 0.00152 & 0.00168 & 0.00185 & 0.00201 & 0.00221 & 0.0024 & 0.0026 \\
St. Dev. & 0.03901 & 0.041 & 0.043 & 0.045 & 0.047 & 0.049 & 0.051 \\
Sharpe Ratio & 0.17741 & 0.18841 & 0.19631 & 0.20288 & 0.20668 & 0.20791 & 0.2089 \\
Skewness & -0.49 & -0.2684 & -0.5371 & -0.6071 & -0.6157 & -0.6175 & -0.692 \\
Kurtosis & 3 & 3 & 3 & 3 & 3 & 3 & 3.0272 \\
\hline
\end{tabular}

Source: Author's calculations.

\section{Efficient Frontiers}

Mean-variance, mean-skewness, mean-kurtosis optimized efficient frontiers are shown in Figure 1 in blue, orange and grey. Horizontal $x$-axis shows risk and vertical $y$-axis show expected returns. Mean-skewness and mean-kurtosis efficient frontiers are below the mean-variance frontier, which shows the risk embeddedness. Our results confirm the argument that mean-variance higher returns do not include the true presence of risk in form of skewness and kurtosis. Apparently, the mean-variance optimized portfolios are more attractive and show superior performance compared to higher-order moment adjusted portfolios. The high returns are coming at the cost of asymmetric and high kurtosis risk. Interestingly, most investors are not familiar about these types of risk. The results emphasize the inclusion of higher moments of risk when optimizing the portfolios. The inclusion of optimization not only helps investors from unnecessary and unexpected losses when volatility is high but also help in achieving the sustainable expected returns. The best possible portfolios for an investor after the inclusion of different risk preferences in our experiment from mean-variance are Portfolios 2, 3 and 4, while for mean-skewness the Portfolios are 4, 1 and 3. The mean-kurtosis portfolios could be 2, 1 and 3 as per preferences. This study confirms that in the presence of higher risk moments (asymmetry and kurtosis), the portfolios based on mean-variance are overpriced, unpredictable and unsustainable. This study contributes while forming various portfolios with diversification options in emerging markets. Our contribution extends for investors with different risk preferences by providing them proportioned options for investment in these markets. This study provides investors, financial managers and other potential investors help in sustainable portfolio formulization, especially in the presence of higher moments of risk.

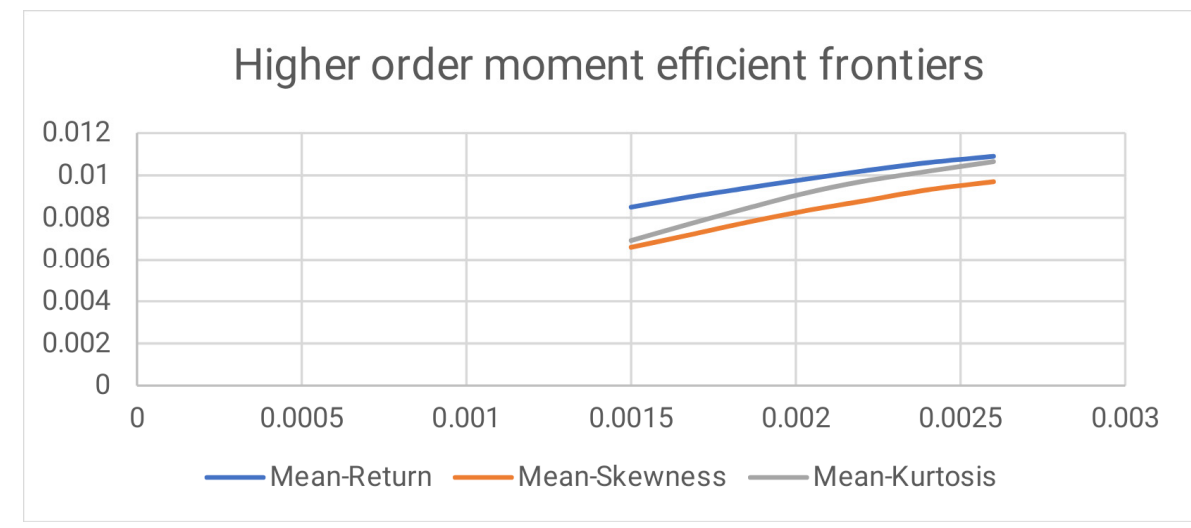

Figure 1. Higher-Order Moments Efficient Frontiers. 


\section{Conclusions}

Although modern portfolio theory introduces a vital volatility concept and a base for mean-variance portfolio optimization, the once very popular normality assumption about financial time series while optimizing portfolios based on mean-variance is no more valid because of skewed and volatility clustering phenomena. The normality assumption and mean-variance optimization understate the associated risk by assuming that the variance is proficient enough to tackle all the investment risk. Many studies have confirmed the presence of asymmetry and excess kurtosis in stock returns. The presence of higher-order moments of risk confirms the need of their inclusion to see if the expected returns are sustainable or overestimated. We chose to use the PGP approach for the incorporation of higher-order moments of risk for portfolio optimization of eight market indices. Our study confirms the presence of asymmetry (negative skewness) and kurtosis. The mean-variance optimization possibly does not provide an acceptable solution with various investors' risk preferences. This study's results are in line with those that confirm the skewness and kurtosis presence in other markets $[12,13,30]$ and show a vital link between returns and higher moments of risk (skewness and kurtosis). This is an important phenomenon because traditionally mean-variance optimization is assumed that embeds all the risk associated with returns. Those investors who know the presence of skewness and kurtosis and want to take care of these risks must settle on a lower return in accumulation to variance. This paper also concludes that the mean-variance-based efficient frontiers are not accurate or efficient frontiers, and investors may misallocate the proportion of their investment which could force them to make sub-optimal decisions. Due to this misallocation the wish to achieve sustainable expected returns cannot be fulfilled, and this could increase volatility and panic among investors. This can be seen in efficient frontier figures, where inclusion of these higher moments pushes the optimized portfolios and efficient frontier downwards. This downward shift in curves shows the importance of skewness and kurtosis, and how they impact significantly on allocation decisions to achieve sustainable and optimal portfolios.

Author Contributions: K.I.K. carried out the main conception and draft the article and participated in the sequence alignment and drafted the manuscript; S.M.W.A.N. participation in the design of study and perform the statistical data analysis; M.M.G. conceived the scheme of study, and participate in its design; R.S.I.A. Worked on the coordination and critically proofread the manuscript. All authors have read and agreed to the published version of the manuscript.

Funding: This research received no external funding.

Conflicts of Interest: The authors declare no conflict of interest.

\section{Appendix A}

Table A1. Variance-Co-Variance.

\begin{tabular}{ccccccccc}
\hline & SCI & HSI & CNX500 & FTSE & KSE100 & STI & KOPSI & TESEC \\
\hline SCI & 0.0074895 & 0.0032548 & 0.0029122 & 0.0016288 & 0.0002555 & 0.0023478 & 0.0003431 & 0.0011710 \\
HSI & 0.0032548 & 0.0040197 & 0.0033017 & 0.0015251 & 0.0008409 & 0.0029272 & 0.0004600 & 0.0006613 \\
CNX500 & 0.0029122 & 0.0033017 & 0.0064646 & 0.0016098 & 0.0015517 & 0.0029435 & 0.0008256 & 0.0012378 \\
FTSE & 0.0016288 & 0.0015251 & 0.0016098 & 0.0013958 & 0.0006238 & 0.0014700 & 0.0005888 & 0.0006818 \\
KSE100 & 0.0002555 & 0.0008409 & 0.0015517 & 0.0006238 & 0.0063660 & 0.0006084 & 0.0006184 & 0.0012232 \\
STI & 0.0023478 & 0.0029272 & 0.0029435 & 0.0014700 & 0.0006084 & 0.0030373 & 0.0007480 & 0.0009782 \\
KOPSI & 0.0003431 & 0.0004600 & 0.0008256 & 0.0005888 & 0.0006184 & 0.0007480 & 0.0024642 & 0.0019337 \\
TESEC & 0.0011710 & 0.0006613 & 0.0012378 & 0.0006818 & 0.0012232 & 0.0009782 & 0.0019337 & 0.0032575 \\
\hline
\end{tabular}


Table A2. Skewness-Co-Skewness Matrices.

\begin{tabular}{|c|c|c|c|c|c|c|c|c|}
\hline 1 & SCI & HSI & CNX500 & FTSE & KSE100 & STI & KOPSI & TESEC \\
\hline SCI & -0.00034 & -0.00032 & -0.00037 & -0.00019 & -0.0001 & -0.00028 & $-9.261 \mathrm{E}-05$ & $1.583 \mathrm{E}-05$ \\
\hline HSI & -0.000316 & -0.00023 & -0.00027 & -0.000143 & $5.74 \mathrm{E}-06$ & -0.00022 & $-8.649 \mathrm{E}-05$ & $-5.587 \mathrm{E}-05$ \\
\hline CNX500 & -0.00037 & -0.00027 & -0.00034 & -0.000181 & $-4.39 \mathrm{E}-05$ & -0.000259 & -0.0001031 & $-3.901 E-05$ \\
\hline FTSE & -0.00019 & -0.00014 & -0.00018 & $-7.25 \mathrm{E}-05$ & $-2.09 \mathrm{E}-05$ & -0.000116 & $-5.329 \mathrm{E}-05$ & $-2.987 \mathrm{E}-05$ \\
\hline KSE100 & -0.000105 & 5.74E-06 & $-4.4 \mathrm{E}-05$ & $-2.12 \mathrm{E}-05$ & $2.54 \mathrm{E}-05$ & $-4.46 \mathrm{E}-05$ & $-7.422 \mathrm{E}-05$ & $-7.788 \mathrm{E}-05$ \\
\hline STI & -0.00028 & -0.00022 & -0.00026 & -0.000116 & $-4.49 \mathrm{E}-05$ & -0.000196 & $-8.56 \mathrm{E}-05$ & $-6.876 \mathrm{E}-05$ \\
\hline KOPSI & $-9.26 \mathrm{E}-05$ & $-8.6 \mathrm{E}-05$ & -0.0001 & $-5.33 \mathrm{E}-05$ & $-7.37 \mathrm{E}-05$ & $-8.56 \mathrm{E}-05$ & $-2.916 \mathrm{E}-05$ & $-2.954 \mathrm{E}-05$ \\
\hline TESEC & $1.634 \mathrm{E}-05$ & $-5.7 \mathrm{E}-05$ & $-4.2 \mathrm{E}-05$ & $-3.45 \mathrm{E}-05$ & $-8.4 \mathrm{E}-05$ & $-7.93 \mathrm{E}-05$ & $-3.367 \mathrm{E}-05$ & $-1.091 \mathrm{E}-05$ \\
\hline 2 & SCI & HSI & CNX500 & FTSE & KSE100 & STI & KOPSI & TESEC \\
\hline SCI & -0.000316 & -0.00023 & -0.00027 & -0.000143 & $4.99 \mathrm{E}-06$ & -0.00022 & $-8.649 \mathrm{E}-05$ & $-5.787 \mathrm{E}-05$ \\
\hline HSI & -0.000234 & -0.00021 & -0.00019 & -0.000102 & $-4.29 \mathrm{E}-05$ & -0.000201 & $-4.976 \mathrm{E}-05$ & $-5.492 \mathrm{E}-05$ \\
\hline CNX500 & -0.000269 & -0.00019 & -0.00019 & -0.000126 & $-4.19 \mathrm{E}-05$ & -0.000203 & $-6.597 \mathrm{E}-05$ & $-2.799 \mathrm{E}-05$ \\
\hline FTSE & -0.000143 & -0.0001 & -0.00013 & $-5.39 \mathrm{E}-05$ & $-4.09 \mathrm{E}-06$ & -0.000106 & $-2.706 \mathrm{E}-05$ & $-2.562 \mathrm{E}-05$ \\
\hline KSE100 & $5.744 \mathrm{E}-06$ & $-4.3 \mathrm{E}-05$ & $-4.2 \mathrm{E}-05$ & $-3.91 \mathrm{E}-06$ & -0.00012 & $-4.89 \mathrm{E}-05$ & 3.958E-05 & $3.738 \mathrm{E}-05$ \\
\hline STI & -0.00022 & -0.0002 & -0.0002 & -0.000106 & $-5.01 \mathrm{E}-05$ & -0.000191 & $-6.429 \mathrm{E}-05$ & $-5.964 \mathrm{E}-05$ \\
\hline KOPSI & $-8.65 \mathrm{E}-05$ & $-5 E-05$ & $-6.6 \mathrm{E}-05$ & $-2.71 \mathrm{E}-05$ & $4.19 \mathrm{E}-05$ & $-6.43 \mathrm{E}-05$ & 3.076E-06 & $1.436 \mathrm{E}-05$ \\
\hline TESEC & $-5.67 \mathrm{E}-05$ & $-5.5 \mathrm{E}-05$ & $-2.9 \mathrm{E}-05$ & $-2.49 \mathrm{E}-05$ & 3.92E-05 & $-5.85 \mathrm{E}-05$ & $1.311 \mathrm{E}-05$ & $3.128 \mathrm{E}-05$ \\
\hline 3 & SCI & HSI & CNX500 & FTSE & KSE100 & STI & KOPSI & TESEC \\
\hline SCI & -0.00037 & -0.00027 & -0.00034 & -0.000181 & $-4.34 \mathrm{E}-05$ & -0.000259 & -0.0001031 & $-3.921 E-05$ \\
\hline HSI & -0.000269 & -0.00019 & -0.00019 & -0.000126 & $-4.19 \mathrm{E}-05$ & -0.000203 & $-6.597 \mathrm{E}-05$ & $-3.036 \mathrm{E}-05$ \\
\hline CNX500 & -0.000335 & -0.00019 & -0.00025 & -0.000165 & -0.00011 & -0.000208 & $-8.18 \mathrm{E}-05$ & $-2.752 \mathrm{E}-05$ \\
\hline FTSE & -0.000181 & -0.00013 & -0.00017 & $-8.48 \mathrm{E}-05$ & $-8.52 \mathrm{E}-06$ & -0.000131 & $-4.309 \mathrm{E}-05$ & $-2.357 \mathrm{E}-05$ \\
\hline KSE100 & $-4.42 \mathrm{E}-05$ & $-4.2 \mathrm{E}-05$ & -0.00011 & $-8.63 \mathrm{E}-06$ & $-6.24 \mathrm{E}-05$ & $-5.21 \mathrm{E}-05$ & 2.011E-05 & $1.642 \mathrm{E}-05$ \\
\hline STI & -0.000259 & -0.0002 & -0.00021 & -0.000131 & $-5.49 \mathrm{E}-05$ & -0.000198 & $-7.368 \mathrm{E}-05$ & $-4.632 \mathrm{E}-05$ \\
\hline KOPSI & -0.000103 & $-5.99 \mathrm{E}-05$ & $-8.04 \mathrm{E}-05$ & $-4.31 \mathrm{E}-05$ & $2.03 \mathrm{E}-05$ & $-6.98 \mathrm{E}-05$ & 1.819E-06 & 2.134E-05 \\
\hline TESEC & $-4.19 \mathrm{E}-05$ & $-3.02 \mathrm{E}-05$ & $-2.70 \mathrm{E}-05$ & $-2.49 \mathrm{E}-05$ & $1.68 \mathrm{E}-05$ & $-4.77 \mathrm{E}-05$ & $2.074 \mathrm{E}-05$ & $4.745 \mathrm{E}-05$ \\
\hline 4 & SCI & HSI & CNX500 & FTSE & KSE100 & STI & KOPSI & TESEC \\
\hline SCI & -0.00019 & -0.00014 & -0.00018 & $-7.25 \mathrm{E}-05$ & $-2.1 \mathrm{ES}-05$ & -0.000116 & $-5.329 \mathrm{E}-05$ & $-2.987 \mathrm{E}-05$ \\
\hline HSI & -0.000143 & -0.0001 & -0.00013 & $-5.39 \mathrm{E}-05$ & $-3.90 \mathrm{E}-06$ & -0.000106 & $-2.706 \mathrm{E}-05$ & $-2.503 E-05$ \\
\hline CNX500 & -0.000181 & -0.00013 & -0.00017 & $-8.48 \mathrm{E}-05$ & $-9.08 \mathrm{E}-06$ & -0.000131 & $-4.309 \mathrm{E}-05$ & $-2.509 \mathrm{E}-05$ \\
\hline FTSE & $-7.25 \mathrm{E}-05$ & $-5.34 \mathrm{E}-05$ & $-8.61 \mathrm{E}-05$ & $-2.97 \mathrm{E}-05$ & $4.06 \mathrm{E}-06$ & $-5.94 \mathrm{E}-05$ & $-1.828 \mathrm{E}-05$ & $-7.998 \mathrm{E}-06$ \\
\hline KSE100 & $-2.12 \mathrm{E}-05$ & $-4.08 \mathrm{E}-06$ & $-9.41 E-06$ & 4.07E-06 & $8.14 \mathrm{E}-06$ & $-1.45 \mathrm{E}-05$ & $9.449 \mathrm{E}-06$ & $1.283 \mathrm{E}-05$ \\
\hline STI & -0.000116 & -0.00023 & -0.00013 & $-6.06 \mathrm{E}-05$ & $-1.04 \mathrm{E}-05$ & -0.000112 & $-3.684 \mathrm{E}-05$ & $-3.002 \mathrm{E}-05$ \\
\hline KOPSI & $-5.33 \mathrm{E}-05$ & $-3.08 \mathrm{E}-05$ & $-4.21 \mathrm{E}-05$ & $-2.08 \mathrm{E}-05$ & $9.45 \mathrm{E}-06$ & $-3.68 \mathrm{E}-05$ & $-2.008 \mathrm{E}-07$ & $1.988 \mathrm{E}-05$ \\
\hline TESEC & $-3.45 \mathrm{E}-05$ & $-3.06 \mathrm{E}-05$ & $-2.5 \mathrm{E}-05$ & $-7.17 \mathrm{E}-06$ & 1.33E-05 & $-2.99 \mathrm{E}-05$ & 2.026E-05 & $1.422 \mathrm{E}-05$ \\
\hline 5 & SCI & HSI & CNX500 & FTSE & KSE100 & STI & KOPSI & TESEC \\
\hline SCI & -0.000105 & $6.99 \mathrm{E}-06$ & $-4.62 \mathrm{E}-05$ & $-2.12 \mathrm{E}-05$ & $2.54 \mathrm{E}-05$ & $-4.46 \mathrm{E}-05$ & $-7.422 \mathrm{E}-05$ & $-8.553 \mathrm{E}-05$ \\
\hline HSI & $5.744 \mathrm{E}-06$ & $-3.99 \mathrm{E}-05$ & $-4.2 \mathrm{E}-05$ & $-3.91 \mathrm{E}-06$ & -0.00013 & $-4.89 \mathrm{E}-05$ & 3.958E-05 & 4.022E-05 \\
\hline CNX500 & $-4.380 \mathrm{E}-05$ & $-3.78 \mathrm{E}-05$ & -0.00011 & $-8.63 \mathrm{E}-06$ & $-5.91 \mathrm{E}-05$ & $-5.21 \mathrm{E}-05$ & $2.011 \mathrm{E}-05$ & $2.057 \mathrm{E}-05$ \\
\hline FTSE & $-2.124 \mathrm{E}-05$ & $-2.76 \mathrm{E}-06$ & $-9.06 \mathrm{E}-06$ & $4.02 \mathrm{E}-06$ & $8.42 \mathrm{E}-06$ & $-1.35 \mathrm{E}-05$ & $9.449 \mathrm{E}-06$ & $1.273 \mathrm{E}-05$ \\
\hline KSE100 & 2.541E-05 & -0.00024 & $-5.99 \mathrm{E}-05$ & $8.44 \mathrm{E}-06$ & -0.00081 & $1.35 \mathrm{E}-05$ & 0.0002088 & 0.0004378 \\
\hline STI & $-4.512 \mathrm{E}-05$ & $-5.08 \mathrm{E}-05$ & $-5.34 \mathrm{E}-05$ & $-2.01 \mathrm{E}-05$ & $2.08 \mathrm{E}-05$ & $-4.95 \mathrm{E}-05$ & $-8.537 \mathrm{E}-07$ & $5.078 \mathrm{E}-06$ \\
\hline KOPSI & $-7.592 \mathrm{E}-05$ & $4.89 \mathrm{E}-05$ & $2.01 \mathrm{E}-05$ & 8.95E-06 & 0.000209 & $-8.54 \mathrm{E}-07$ & $-2.462 \mathrm{E}-05$ & $-1.375 \mathrm{E}-05$ \\
\hline TESEC & $-7.982 \mathrm{E}-05$ & 4.02E-05 & $1.59 \mathrm{E}-05$ & $1.33 \mathrm{E}-05$ & 0.000169 & 4.73E-06 & $-1.192 \mathrm{E}-05$ & $-2.546 \mathrm{E}-06$ \\
\hline 6 & SCI & HSI & CNX500 & FTSE & KSE100 & STI & KOPSI & TESEC \\
\hline SCI & -0.00028 & -0.00022 & -0.00026 & -0.000116 & $-4.51 \mathrm{E}-05$ & -0.000196 & $-8.56 \mathrm{E}-05$ & $-8.076 \mathrm{E}-05$ \\
\hline HSI & -0.00022 & -0.0002 & -0.0002 & -0.000106 & $-4.92 \mathrm{E}-05$ & -0.000191 & $-6.429 \mathrm{E}-05$ & $-6.041 \mathrm{E}-05$ \\
\hline CNX500 & -0.000259 & -0.0002 & -0.00021 & -0.000131 & $-4.99 \mathrm{E}-05$ & -0.000198 & $-7.368 \mathrm{E}-05$ & $-5.028 \mathrm{E}-05$ \\
\hline FTSE & -0.000116 & -0.00011 & -0.00013 & $-5.94 \mathrm{E}-05$ & $-1.52 \mathrm{E}-05$ & -0.000112 & $-3.684 \mathrm{E}-05$ & $-3.028 \mathrm{E}-05$ \\
\hline KSE100 & $-4.46 \mathrm{E}-05$ & $-4.89 \mathrm{E}-05$ & $-5.19 \mathrm{E}-05$ & $-1.45 \mathrm{E}-05$ & $2.02 \mathrm{E}-05$ & $-5.2 \mathrm{E}-05$ & $-8.537 \mathrm{E}-07$ & 5.087E-06 \\
\hline STI & -0.000196 & -0.00021 & -0.0002 & -0.000112 & $-4.98 \mathrm{E}-05$ & -0.000188 & $-7.382 \mathrm{E}-05$ & $-5.111 \mathrm{E}-05$ \\
\hline KOPSI & $-8.56 \mathrm{E}-05$ & $-6.36 \mathrm{E}-05$ & $-7.26 \mathrm{E}-05$ & $-3.68 \mathrm{E}-05$ & $-8.52 \mathrm{E}-07$ & $-7.38 \mathrm{E}-05$ & $-9.628 \mathrm{E}-06$ & $-3.075 E-06$ \\
\hline TESEC & $-7.93 \mathrm{E}-05$ & $-6.08 \mathrm{E}-05$ & $-4.92 \mathrm{E}-05$ & $-2.99 \mathrm{E}-05$ & $4.74 \mathrm{E}-06$ & $-5.11 \mathrm{E}-05$ & $-2.816 \mathrm{E}-06$ & $9.985 \mathrm{E}-06$ \\
\hline
\end{tabular}


Table A2. Cont.

\begin{tabular}{ccccccccc}
\hline $\mathbf{7}$ & SCI & HSI & CNX500 & FTSE & KSE100 & STI & KOPSI & TESEC \\
\hline SCI & $-9.26 E-05$ & $-8.72 \mathrm{E}-05$ & -0.0001 & $-5.33 \mathrm{E}-05$ & $-7.4 \mathrm{E}-05$ & $-8.56 \mathrm{E}-05$ & $-2.916 \mathrm{E}-05$ & $-3.429 \mathrm{E}-05$ \\
HSI & $-8.65 \mathrm{E}-05$ & $-5.01 \mathrm{E}-05$ & $-6.59 \mathrm{E}-05$ & $-2.71 \mathrm{E}-05$ & $3.96 \mathrm{E}-05$ & $-6.43 \mathrm{E}-05$ & $3.076 \mathrm{E}-06$ & $1.245 \mathrm{E}-05$ \\
CNX500 & -0.000103 & $-5.98 \mathrm{E}-05$ & $-8.21 \mathrm{E}-05$ & $-4.31 \mathrm{E}-05$ & $2.01 \mathrm{E}-05$ & $-7.37 \mathrm{E}-05$ & $1.819 \mathrm{E}-06$ & $2.108 \mathrm{E}-05$ \\
FTSE & $-5.42 \mathrm{E}-05$ & $-3.09 \mathrm{E}-05$ & $-4.29 \mathrm{E}-05$ & $-1.83 \mathrm{E}-05$ & $9.45 \mathrm{E}-06$ & $-3.57 \mathrm{E}-05$ & $-2.008 \mathrm{E}-07$ & $2.116 \mathrm{E}-05$ \\
KSE100 & $-7.31 \mathrm{E}-05$ & $4.04 \mathrm{E}-05$ & $2.01 \mathrm{E}-05$ & $9.23 \mathrm{E}-06$ & 0.000209 & $-8.54 \mathrm{E}-07$ & $-2.462 \mathrm{E}-05$ & $-1.193 \mathrm{E}-05$ \\
STI & $-8.49 \mathrm{E}-05$ & $-6.38 \mathrm{E}-05$ & $-7.46 \mathrm{E}-05$ & $-4.09 \mathrm{E}-05$ & $-8.5 \mathrm{E}-07$ & $-7.49 \mathrm{E}-05$ & $-9.628 \mathrm{E}-06$ & $-3.097 \mathrm{E}-06$ \\
KOPSI & $-2.92 \mathrm{E}-05$ & $3.12 \mathrm{E}-06$ & $1.82 \mathrm{E}-06$ & $-2.01 \mathrm{E}-07$ & $-2.5 \mathrm{E}-05$ & $-9.63 \mathrm{E}-06$ & $-6.802 \mathrm{E}-05$ & $-2.246 \mathrm{E}-05$ \\
TESEC & $-3.37 \mathrm{E}-05$ & $1.21 \mathrm{E}-05$ & $2.07 \mathrm{E}-05$ & $2.03 \mathrm{E}-05$ & $-1.2 \mathrm{E}-05$ & $-2.78 \mathrm{E}-06$ & $-2.327 \mathrm{E}-05$ & $-3.998 \mathrm{E}-05$ \\
\hline $\mathbf{8}$ & SCI & HSI & CNX500 & FTSE & KSE100 & STI & KOPSI & TESEC \\
\hline SCI & $1.634 \mathrm{E}-05$ & $-5.81 \mathrm{E}-05$ & $-4.13 \mathrm{E}-05$ & $-3.36 \mathrm{E}-05$ & $-8.4 \mathrm{E}-05$ & $-7.93 \mathrm{E}-05$ & $-3.276 \mathrm{E}-05$ & $-1.099 \mathrm{E}-05$ \\
HSI & $-5.67 \mathrm{E}-05$ & $-5.68 \mathrm{E}-05$ & $-3.05 \mathrm{E}-05$ & $-2.53 \mathrm{E}-05$ & $3.95 \mathrm{E}-05$ & $-5.92 \mathrm{E}-05$ & $1.311 \mathrm{E}-05$ & $3.168 \mathrm{E}-05$ \\
CNX500 & $-4.19 \mathrm{E}-05$ & $-3.08 \mathrm{E}-05$ & $-2.99 \mathrm{E}-05$ & $-2.49 \mathrm{E}-05$ & $1.68 \mathrm{E}-05$ & $-4.77 \mathrm{E}-05$ & $2.074 \mathrm{E}-05$ & $5.096 \mathrm{E}-05$ \\
FTSE & $-3.21 \mathrm{E}-05$ & $-3.05 \mathrm{E}-05$ & $-2.52 \mathrm{E}-05$ & $-8.25 \mathrm{E}-06$ & $1.33 \mathrm{E}-05$ & $-3.09 \mathrm{E}-05$ & $2.128 \mathrm{E}-05$ & $1.243 \mathrm{E}-05$ \\
KSE100 & $-8.32 \mathrm{E}-05$ & $3.91 \mathrm{E}-05$ & $1.59 \mathrm{E}-05$ & $1.33 \mathrm{E}-05$ & 0.000169 & $4.73 \mathrm{E}-06$ & $-1.121 \mathrm{E}-05$ & $-2.356 \mathrm{E}-06$ \\
STI & $-7.93 \mathrm{E}-05$ & $-6.08 \mathrm{E}-05$ & $-4.82 \mathrm{E}-05$ & $-2.99 \mathrm{E}-05$ & $4.82 \mathrm{E}-06$ & $-5.29 \mathrm{E}-05$ & $-2.854 \mathrm{E}-06$ & $9.627 \mathrm{E}-06$ \\
KOPSI & $-4.08 \mathrm{E}-05$ & $1.24 \mathrm{E}-05$ & $2.07 \mathrm{E}-05$ & $2.03 \mathrm{E}-05$ & $-1.22 \mathrm{E}-05$ & $-2.82 \mathrm{E}-06$ & $-2.425 \mathrm{E}-05$ & $-3.9977 \mathrm{E}-05$ \\
TESEC & $-1.12 \mathrm{E}-05$ & $3.13 \mathrm{E}-05$ & $4.66 \mathrm{E}-05$ & $1.36 \mathrm{E}-05$ & $-2.54 \mathrm{E}-06$ & $9.71 \mathrm{E}-06$ & $-4.127 \mathrm{E}-05$ & $-5.097 \mathrm{E}-05$ \\
\hline
\end{tabular}

\section{References}

1. Gökgöz, F.; Atmaca, M.E. Portfolio optimization under lower partial moments in emerging electricity markets: Evidence from Turkey. Renew. Sustain. Energy Rev. 2017, 67, 437-449.

2. Kellner, F.; Lienland, B.; Utz, S. An a posteriori decision support methodology for solving the multi-criteria supplier selection problem. Eur. J. Oper. Res. 2019, 272, 505-522. [CrossRef]

3. Chen, B.; Zhong, J.; Chen, Y. A hybrid approach for portfolio selection with higher-order moments: Empirical evidence from Shanghai Stock Exchange. Expert Syst. Appl. 2020, 145, 113104. [CrossRef]

4. Oikonomou, I.; Platanakis, E.; Sutcliffe, C. Socially responsible investment portfolios: Does the optimization process matter? Br. Account. Rev. 2018, 50, 379-401. [CrossRef]

5. Bernardi, M.; Catania, L. Portfolio optimisation under flexible dynamic dependence modelling. J. Empir. Financ. 2018, 48, 1-18. [CrossRef]

6. Khan, M.S.; Khan, K.I.; Mahmood, S.; Sheeraz, M. Symmetric and asymmetric volatility clustering Via GARCH family models: An evidence from religion dominant countries. Paradigms 2019, 13, $20-25$.

7. AracioĞlu, B.; Demircan, F.; Soyuer, H. Mean-variance-skewness-kurtosis approach to portfolio optimization: An application in İstanbul Stock Exchange. Ege Akad. Bakış Derg. 2011, 11, 9-17.

8. Singh, A.K.; Sahu, R.; Bharadwaj, S. Portfolio evaluation using OWA-heuristic algorithm and data envelopment analysis. J. Risk Financ. 2010, 11, 75-88. [CrossRef]

9. Lux, T.; Marchesi, M. Volatility clustering in financial markets:A microsimulation of interacting agents. Int. J. Theor. Appl. Financ. 2000, 3, 675-702. [CrossRef]

10. Jaffar, Y.; Dewandaru, G.; Masih, M. Exploring Portfolio Diversification Opportunities Through Venture Capital Financing: Evidence from MGARCH-DCC, Markov Switching, and Wavelet Approaches. Emerg.Market. Finac. Trade 2018, 54, 1320-1336. [CrossRef]

11. Ñ́guez, T.-M.; Paya, I.; Peel, D.; Perote, J. Flexible distribution functions, higher-order preferences and optimal portfolio allocation. Quant. Financ. 2019, 19, 699-703. [CrossRef]

12. Naqvi, B.; Mirza, N.; Naqvi, W.A.; Rizvi, S. Portfolio optimisation with higher moments of risk at the Pakistan Stock Exchange. Econ. Res. Ekon. Istraživanja 2017, 30, 1594-1610. [CrossRef]

13. Beedles, W.L. Asymmetry in Australian equity returns. Aust. J. Manag. 1986, 11, 1-12. [CrossRef]

14. Kellner, F.; Utz, S. Sustainability in supplier selection and order allocation: Combining integer variables with Markowitz portfolio theory. J. Clean. Prod. 2019, 214, 462-474. [CrossRef]

15. Wong, W.-K.; Lean, H.H.; McAleer, M.; Tsai, F.-T. Why Are Warrant Markets Sustained in Taiwan but Not in China? Sustainability 2018, 10, 3748. [CrossRef] 
16. de Moraes Dutenkefer, R.; de Oliveira Ribeiro, C.; Morgado Mutran, V.; Eduardo Rego, E. The insertion of biogas in the sugarcane mill product portfolio: A study using the robust optimization approach. Renew. Sustain. Energy Rev. 2018, 91, 729-740. [CrossRef]

17. Sajith, S.G.; Chiu, J.; Wong, W.; Chiam, P.C. Perceptions of psychiatry residents and non-residents on training needs and care related to patients with intellectual disability and mental health problems: A study from Singapore. J. Intellect. Dev. Disabil. 2019, 44, 73-80. [CrossRef]

18. Zhang, Y.; Li, X.; Guo, S. Portfolio selection problems with Markowitz's mean-variance framework: A review of literature. Fuzzy Optim. Decis. Mak. 2018, 17, 125-158. [CrossRef]

19. Leavens, D.H. Diversification of investments. Trust. Estate. 1945, 80, 469-473.

20. Matthies, B.D.; Jacobsen, J.B.; Knoke, T.; Paul, C.; Valsta, L. Utilising portfolio theory in environmental research-New perspectives and considerations. J. Environ. Manag. 2019, 231, 926-939. [CrossRef]

21. Markowitz, H. Portfolio Selection. J. Financ. 1952, 7, 77-91.

22. Tobin, J. Liquidity preference as behavior towards risk. Rev. Econ. Stud. 1958, 25, 65-86. [CrossRef]

23. Lintner, J. Security prices, risk, and maximal gains from diversification. J. Financ. 1965, 20, 587-615.

24. Sharpe, W.F. A simplified model for portfolio analysis. Manag. Sci. 1963, 9, 277-293. [CrossRef]

25. Sharpe, W.F. Capital asset prices: A theory of market equilibrium under conditions of risk. J. Financ. 1964, $19,425-442$.

26. Naqvi, S.M.W.A.; Khan, K.I.; Ghafoor, M.M.; Rizvi, S.K.A. Evidence of volatility clustering and asymmetric behavior of returns in Asian emerging stock markets. Pak. Econ. Soc. Rev. 2019, 57, 163-197.

27. Barillas, F.; Shanken, J. Comparing asset pricing models. J. Financ. 2018, 73, 715-754. [CrossRef]

28. Biglova, A.; Ortobelli, S.; Rachev, S.T.; Stoyanov, S. Different approaches to risk estimation in portfolio theory. J. Portf. Manag. 2004, 31, 103-112. [CrossRef]

29. Beedles, W.L. On the asymmetry of market returns. J. Financ. Quant. Anal. 1979, 14, 653-660. [CrossRef]

30. Aggarwal, R.; Rao, R.P.; Hiraki, T. Skewness and kurtosis in Japanese equity returns: Empirical evidence. J. Financ. Res. 1989, 12, 253-260. [CrossRef]

31. Tseng, J.-J.; Li, S.-P. Quantifying volatility clustering in financial time series. Int. Rev. Financ. Anal. 2012, 23, 11-19. [CrossRef]

32. Ruiz, A.B.; Saborido, R.; Bermúdez, J.D.; Luque, M.; Vercher, E. Preference-based evolutionary multi-objective optimization for portfolio selection: A new credibilistic model under investor preferences. J. Glob. Optim. 2020, 76, 295-315. [CrossRef]

33. Pérez Odeh, R.; Watts, D.; Flores, Y. Planning in a changing environment: Applications of portfolio optimisation to deal with risk in the electricity sector. Renew. Sustain. Energy Rev. 2018, 82, 3808-3823. [CrossRef]

34. Guidolin, M.; Timmermann, A. International asset allocation under regime switching, skew, and kurtosis preferences. Rev. Financ. Stud. 2008, 21, 889-935. [CrossRef]

35. Hong, Y.; Tu, J.; Zhou, G. Asymmetries in stock returns: Statistical tests and economic evaluation. Rev. Financ. Stud. 2007, 20, 1547-1581. [CrossRef]

36. Smimou, K.; Thulasiram, R.K. A simple parallel algorithm for large-scale portfolio problems. J. Risk Financ. 2010, 11, 481-495. [CrossRef]

37. Hafner, R.; Wallmeier, M. Optimal investments in volatility. Fin. Mark. Portf. Manag. 2008, 22, 147-167. [CrossRef]

38. Abdelaziz, F.B.; Aouni, B.; Fayedh, R.E. Multi-objective stochastic programming for portfolio selection. Eur. J. Oper. Res. 2007, 177, 1811-1823. [CrossRef]

39. Peng, Y.; Xiao, Y.; Fu, Z.; Dong, Y.; Zheng, Y.; Yan, H.; Li, X. Precision irrigation perspectives on the sustainable water-saving of field crop production in China: Water demand prediction and irrigation scheme optimization. J. Clean. Prod. 2019, 230, 365-377. [CrossRef]

(C) 2020 by the authors. Licensee MDPI, Basel, Switzerland. This article is an open access article distributed under the terms and conditions of the Creative Commons Attribution (CC BY) license (http://creativecommons.org/licenses/by/4.0/). 